\title{
Pengaruh Leverage, UkuranPerusahan, Kualitas Audit dan Independensi Auditor Terhadap Manajemen Laba Pada Perusahaan Manufaktur Yang Terdaftar di BEI Periode 2015-2017.
}

\author{
Rosmiati $^{1}$, Drs. Jihen Ginting M.,Si Ak.CA ${ }^{2}$ \\ Universitas Negeri Medan
}

\begin{abstract}
Abstrak: The problem in this study is how the influence of leverage, company size, audit quality and auditor independence on earnings management. The purpose of this study was to determine the effect of leverage, firm size, audit quality and auditor independence on earnings management. The population in this study are the entire companies of manufacturing companies listed on the Indonesia Stock Exchange in 2015-2017, which amounted to 143. However, from this population there are 128 annual reports that do not meet the research criteria and which are 15 annual reports in each year due to this study took 3 years of data, the number of samples was 45 annual reports. The analysis technique uses a purposive sampling technique with several criteria. The analysis technique in this study used multiple regression analysis with the help of the SPSS program. The results of this study indicate that Leverage, Company Size, Audit Quality and Auditor Independence simultaneously have no effect on earnings management. Partially Leverage has a negative effect on earnings management, Company Size does not affect earnings management, Audit Quality does not affect earnings management and Auditor Independence does not have an effect on earnings management.
\end{abstract}

Keywords: Leverage, Company Size, Audit Quality, Auditor Independence, Earnings Management. 


\section{Pendahuluan}

Salah satu ukuran perusahaan dikatakan berhasil dan digunakan sebagai dasar pengambilan keputusan adalah laba. Kinerja manajemen perusahaan tercermin pada laba yang terkandung dalam laporan keuangan, sehingga informasi laba merupakan informasi yang penting sebagai dasar pengambilan keputusan investasi. Informasi laba ini sering menjadi target rekayasa tindakan oportunis manajemen untuk memaksimalkan kepentingannya, sehingga dapat merugikan investor. Perilaku mengatur laba perusahaan sesuai dengan keinginan manajemen ini dikenal dengan istilah manajemen laba (earnings management).

Manajemen laba adalah suatu cara yang ditempuh manajemen dalam mengelola perusahaan melalui pemilihan kebijakan akuntansi tertentu dengan tujuan untuk meningkatkan laba bersih dan nilai perusahaan sesuai dengan harapan manajemen. Manajemen laba timbul sebagai dampak persoalan keagenan yaitu ketidakselarasan kepentingan antara manajer dan pemilik perusahaan yang dikarenakan adanya asimetri informasi. Asimetri informasi adalah suatu kondisi dimana adanya ketidakseimbangan dalam perolehan informasi antara manajemen dan pemegang saham dimana manajemen memiliki informasi yang lebih dibanding dengan pihak eksternal.

Untuk dapat mengembalikan kepercayaan pihak pemakai laporan keuangan, sangat diharapkan kualitas audit yang baik, namun tidak dapat dipungkiri bahwa laporan keuangan perusahaan akan diaudit oleh auditor yang memiliki kualitas yang berbeda-beda. Jasa audit merupakan alat monitoring terhadap kemungkinan timbulnya konflik kepentingan antara pemilik dan manajer serta antara pemegang saham dengan jumlah kepemilikan yang berbeda. Jasa audit dapat mengurangi asimetri informasi antara manajer dan stakeholder perusahaan dengan memperbolehkan pihak luar untuk memeriksa validitas laporan keuangan.

Selain kualitas audit, faktor lain yang dapat mempengaruhi manajemen laba yaitu ukuran perusahaan. Ukuran perusahaan yaitu besar kecilnya perusahaan. Penelitian ukuran perusahaan dapat menggunakan tolak ukur aset akhir tahun. Total penjualan juga dapat digunakan dalam mengukur besarnya perusahaan.

\section{Landasan Teori}

\subsection{Teori Keagenan}

Timbulnya praktik manajemen laba dapat dijelaskan dengan teori agensi yang disebabkan adanya asimetri informasi. Asimetri informasi merupakan suatu kondisi adanya ketidakseimbangan perolehan informasi antara pihak manajemen dan pemegang saham. Manajer memiliki lebih banyak informasi daripada pemegang saham karena manajer sebagai pengelola perusahaan. Informasi yang lebih sedikit yang dimiliki oleh pemegang saham dapat memicu manajer menggunakanposisinya dalam perusahaan untuk mengelola laba yang dilaporkan (Zou dan Elder 2004).

Kondisi ini menyebabkan munculnya konflik kepentingan antara pemegang saham (prinsipal) dengan manajer (agen), dimana antara agen dan prinsipal ingin memaksimumkan kesejahteraan masing-masing dengan informasi yang dimiliki. Dalam kondisi asimetri seperti ini perlu ada orang ketiga sebagai penengah antara manajer dan pemegang saham yang berperan untuk mengontrol atau sebagai mediator yang mengawasi kinerja agen agar sesuai dengan harapan dan keinginan principal. Auditor merupakan pihak yang dianggap mampu menjembatani kepentingan pihak prinsipal (shareholder) dan pihak manajer (agent) dalam mengelola keuangan perusahaan.

\subsection{Pengembangan Hipotesis}

\subsubsection{Pengaruh Leverage Terhadap Manajemen Laba}

Perusahaan dengan tingkat leverage yang tinggi akan termotivasi untuk melakukan manajemen laba agar terhindar dari pelanggaran perjanjian utang, dengan demikian perusahaan yang mempunyai rasio leverage tinggi berarti memiliki proporsi utang lebih besar dibandingkan dengan proporsi shareholder equity nya. Hal ini akan cenderung membuat manajemen melakukan manipulasi dalam bentuk manajemen laba. Semakin tinggi rasio leverage maka akan semakin tinggi juga tingkat manajamen laba. Hal ini diperjelas Utari dan Sari (2016) yang menyebutkan bahwa leverage yang tinggi disebabkan oleh kesalahan manajemen dalam mengelola keuangan perusahaan atau penerapan strategi yang kurang tepat dari pihak manajemen. 


\subsubsection{Pengaruh Ukuran Perusahaan terhadap Manajemen Laba}

Ukuran perusahaan merupakan salah satu faktor pendorong praktek manajemen laba. Menurut Santana dan Wirakusuma (2016) semakin besar perusahaan maka akan mendapat perhatian dari banyak pihak terutama pemerintah dan masyarakat. Perusahaan akan mempermainkan jumlah laba untuk menarik investor agar menanamkan saham pada perusahaan. Juniarti dan Corolina (2005) juga menyatakan perusahaan yang berukuran besar cenderung untuk menghindari laba yang berfluktuatif drastis. Hal ini memungkinkan perusahaan yang lebih besar berkesempatan melakukan manajemen laba dibandingkan perusahaan kecil.

\subsubsection{Pengaruh Kualitas Audit terhadap Manajemen Laba}

Tujuan dari audit laporan keuangan adalah untuk memberikan kepastian mengenai integritas dari laporan keuangan yang disajikan oleh pihak manajemen. Kepastian mengenai relevansi dan keandalan dari laporan keuangan perusahaan sangat diperlukan untuk membantu pihak eksternal dalam mengambil suatu keputusan bisnis (Mayangsari 2004).

Kualitas audit dalam penelitian ini diukur dengan proksi ukuran KAP, karena diasumsikan akan berpengaruh terhadap hasil audit yang dilakukan oleh auditornya. Auditor yang bekerja di KAP Big Four dianggap lebih berkualitas karena auditor tersebut dibekali oleh serangkaian pelatihan dan prosedur serta memiliki program audit yang dianggap lebih akurat dan efektif dibandingkan dengan auditor dari KAP non-Big Four (Isnanta, 2008). Sehingga perusahaan yang diaudit oleh KAP the big four dimungkinkan tidak melakukan manajemen laba.

\subsubsection{Pengaruh Independensi Auditor Terhadap Manajemen Laba}

Independensi auditor akan berdampak terhadap pendeteksian manajemen laba. Semakin lama auditor melaksanakan audit pada suatu perusahaan, maka auditor dianggap tidak independen (Welvin, 2010). Berdasarkan uraian tersebut, maka bisa disimpulkan terdapat pengaruh independensi auditor terhadap manajemen laba.

\section{Gambar 1}

Kerangka Berfikir Penelitian

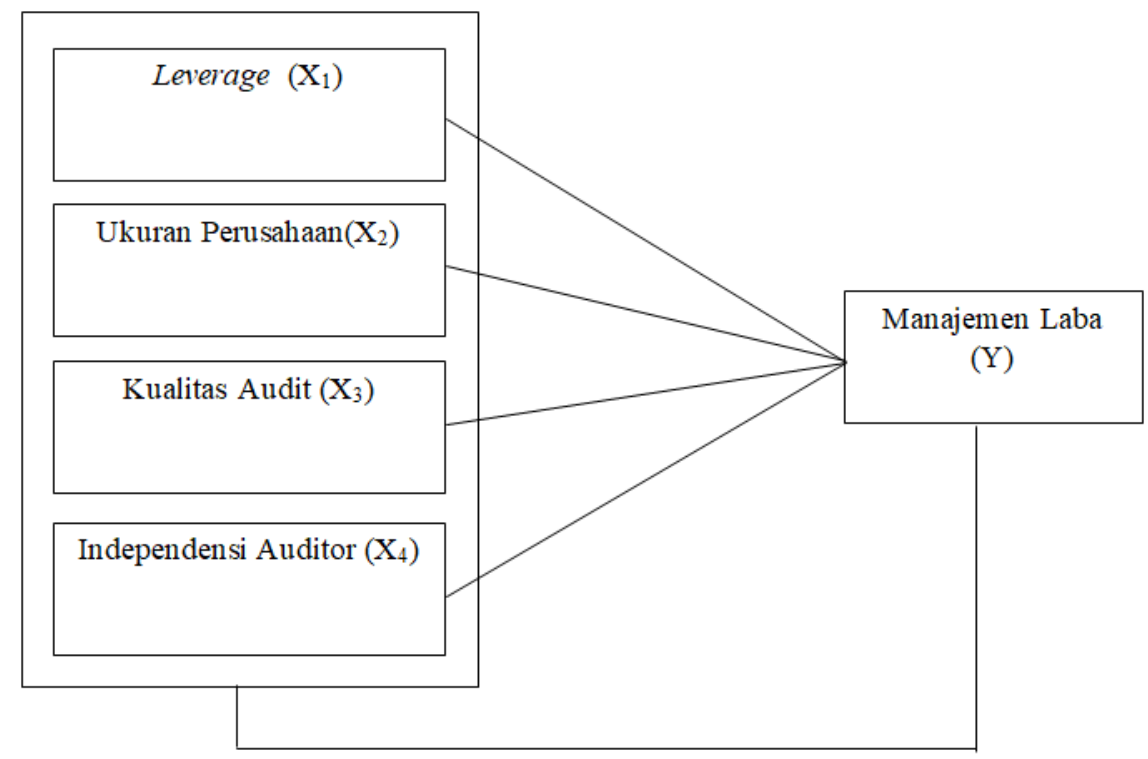

\subsection{Hipotesis}

H1 : Leverage berpengaruh terhadap manajemen laba

H2 : Ukuran Perusahaan berpengaruh terhadap manajemen laba

H3 : Kualitas Audit berpengaruh terhadap manajemen laba

H4 : Independensi Auditor berpengaruh terhadap manajemen laba 
H5 : Leverage,Ukuran Perusahaan, Kualitas audit dan Independensi Auditor secara simultan berpengaruh terhadap manajemen laba.

\section{Metode Penelitian}

\subsection{Populasi dan Sampel Penelitian}

Penelitian ini memiliki populasi seluruh data laporan keuangan perusahaan manufaktur yang tercatat di Bursa Efek Indonesia tahun 2015-2017. Menurut BEI, sektor-sektor yang tergolong sebagai perusahaan manufaktur adalah perusahaan yang bergerak di bidang indutri dasar dan kimia, aneka industri, dan industri barang konsumsi. Metode pengambilan sampel dalam penelitian ini menggunakan purposive sampling. Purposive sampling adalah memilih sampel berdasarkan karakteristik anggota sampel yang disesuaikan dengan maksud peneliti.

Adapun karakteriktik penarikan sampel yang digunakan oleh peneliti adalah sebagai berikut :

a. Perusahaan manufaktur yang terdaftar di Bursa Efek Indonesia pada periode penelitian 2015-2017.

b. Perusahaan manufaktur yang mempublikasikan annual report yang sudah diaudit dan berakhir 31 Desember secara konsisten pada periode penelitian 2015-2017.

c. Perusahaan manufaktur yang mengalami laba selama periode penelitian.

d. Perusahaan tidak baru listing atau delisting pada masa periode penelitian.

e. Perusahaan manufaktur yang memiliki ketersediaan data lengkap yang dibutuhkan dalam penelitian ini

\subsection{Defenisi Operasional Dan Pengukuran Variabel}

\subsubsection{Manajemen Laba}

Manajemen Laba adalah tindakan mempengaruhi laba dengan cara memanipulasi data atau informasi akuntansi agar tingkat laba yang yang tercatat dalam laporan keuangan sesuai dengan yang diinginkan. Informasi akuntansi yang dimaksud seperti pendapatan, ukuran perusahaan, umur perusahaan dan laba kotor. Manajemen laba dalam penelitian ini di ukur dengan menggunakan discretionary accruals. Dechow (2002) berpendapat discretionary accrual suatu perusahaan dapat dihitung melalui tahap berikut :

1. Menentukan nilai total akrual, yang merupakan selisih antara laba bersih dan arus kas operasi.TAit $=$ NIit - CFOit

2. Menentukan nilai parameter 1,2, dan 3 dengan Modified Model Jones (1991).

TAit $=\alpha 1+\alpha 2 \Delta$ REVit $+\alpha 3$ PPEit + eit

TAit/Ait-1 $=\alpha 1(1 /$ Ait-1 $)+\alpha 2(\Delta$ REVit/Ait-1) $+\alpha 3($ PPEit/Ait-1 $)+\varepsilon i t$

Nilai parameter 1,2, dan 3 diestimasi dengan persamaan regresi Ordinary Least Square (OLS)

3. Menggunakan nilai parameter 1,2 , dan 3 , nilai non discretionary accrual dapat dihitung dengan rumus :

NDAit $=\alpha 1(1 /$ Ait-1 $)+\alpha 2(\Delta$ REVit/Ait-1 $-\Delta$ RECit/Ait-1) $+\alpha 3($ PPEit/Ait-1 $)+\varepsilon i t$

4. $\quad$ DAit $=$ TAit - NDAit

\subsubsection{Leverage}

Leverage adalah hutang yang digunakan perusahaan untuk membiayai asetnya dalam rangka menjalankan operasional perusahaan. Rasio leverage mengukur sejauh mana aktiva perusahaan telah dibiayai oleh penggunaan hutang. Semakin tinggi rasio leverage maka semakin banyak aktiva yang didanai hutang oleh pihak kreditur. Sehingga menunjukkan resiko perusahaan dalam pelunasannya. Hal ini dapat memicu terjadinya praktik manajemen laba. Leverage dapat diukur dengan menggunakan rasio total utang terhadap aset.

$$
\text { DER }=\frac{\text { Total Utang }}{\text { Total Ekuitas }} \times 100 \%
$$




\subsubsection{Ukuran Perusahaan}

Ukuran perusahaan adalah besar kecilnya perusahaan dilihat dati total aset maupun total ekuitas perusahaan tersebut. Perusahaan yang besar lebih diperhatikan oleh masyarakat sehingga mereka akan lebih berhati-hati dalam melakukan pelaporan keuangan sehingga memberi dampak perusahaan tersebut melaporkan kondisinya lebih akurat. Untuk menghitung ukuran perusahaan menggunakan logaritma natural. Konversi kebentuk logaritma natural ini bertujuan untuk membuat data total asset terdistribusi normal. Variabel ini diukur dengan formula berikut.

$$
\text { Firm size }=\text { Ln Total Assets }
$$

Keterangan :

$$
\begin{array}{ll}
\text { Firm Size } & =\text { Ukuran Perusahaan } \\
\text { Ln } & =\text { Logaritma natural dari Total Assets }
\end{array}
$$

\subsubsection{Kualitas Audit}

Kualitas audit adalah probabilitas gabungan untuk mendeteksi dan melaporkan kesalahan yang material dalam laporan keuangan. Kualitas audit dipandang sebagai kemampuan untuk mempertinggi kualitas pelaporan keuangan perusahaan. Dengan kualitas audit yang tinggi diharapkan mampu meningkatkan kepercayaan investor. Kualitas audit diproksikan dengan ukuran KAP (KAP The big- 4 dan KAP Non The big- 4). Kualitas audit diukur dengan skala nominal melalui variabel dummy. Angka1 digunakan untuk mewakili perusahaan yang diaudit oleh KAP Big Four danangka 0 digunakan untuk mewakili perusahaan yang tidak diaudit oleh KAPnon-Big Four.

\subsubsection{Independensi Auditor}

Independensi Auditor adalah kemampuan auditor dalam melaksanakan tugas auditnya tanpa adanya pengaruh dari pihak lain. Auditor harus jujur, tidak mudah dipengaruhi dan tidak memihak kepentingan siapapun, karena auditor tersebut melakukan pekerjaanya umtuk kepentingan umum. Independensi auditor melalui proksi lama penugasan audit diukur menggunakan skala nominal dengan variabel dummy. Angka 1 digunakan untuk mewakili perusahaan yang menggunakan auditor yang sama dalam 3 tahun, yang berarti tidak memiliki sikap independen. Angka 0 digunakan untuk perusahaan yang mengganti auditornya dalam waktu kurang dari 3 tahun, yang berarti memiliki sikap independen.

\subsection{Metode Analisis Data}

Teknik analisis data yang digunakan peneliti adalah dengan metode analisis regresi berganda.

$$
\mathrm{Y}=\mathrm{a}+\mathrm{b} 1 \mathrm{X} 1+\mathrm{b} 2 \mathrm{X} 2+\mathrm{b} 3 \mathrm{X} 3+\mathrm{b} 4 \mathrm{X} 4+\mathrm{e}
$$

Keterangan :

$$
\begin{array}{ll}
\mathrm{Y} & =\text { Manajemen Laba } \\
\mathrm{a} & =\text { Konstanta } \\
\mathrm{b} 1-4 & =\text { Koefisien Regresi } \\
\mathrm{X} 1 & =\text { Kualitas Audit } \\
\mathrm{X} 2 & =\text { Independensi Auditor } \\
\mathrm{X} 3 & =\text { Leverage } \\
\mathrm{X} 4 & =\text { Ukuran Usaha }
\end{array}
$$

\section{Hasil}

\subsection{Statistik Deskriptif}

Statistik deskriptif merupakan proses transformasi data penelitian dalam bentuk tabulasi sehingga mudah dipahami dan diinterpretasikan. Sebelum membahas pengujian atas hipotesis yang diajukan, berikut akan diuraikan beberapa informasi yang diperoleh dari sampel penelitian melalui statistik deskriptif. 
Tabel4.1

StatistikDesktriptif

\begin{tabular}{|l|r|r|r|r|r|}
\hline & $\mathrm{N}$ & \multicolumn{1}{|c|}{ Minimum } & \multicolumn{1}{c|}{ Maximum } & \multicolumn{1}{c|}{ Mean } & Std. Deviation \\
\hline ManajemenLaba & 45 & -.19 & .17 & -.0320 & .06754 \\
Leverage & 45 & .11 & 2.19 & .7760 & .56133 \\
Ukuran Perusahaan & 45 & 26.67 & 32.71 & 28.5269 & 1.33501 \\
Kualitas Audit & 45 & .00 & 1.00 & .3556 & .48409 \\
Independensi Auditor & 45 & .00 & 1.00 & .5333 & .50452 \\
Valid N (listwise) & 45 & & & \\
\hline
\end{tabular}

\subsection{Analisis Regresi Berganda}

Analisis regresi berganda pada dasarnya adalah studi mengenai ketergantungan variabel dependen (terikat) dengan satu atau lebih variabel independen (variabel penjelas/bebas) dengan tujuan untuk mengestimasi dan/atau memprediksi rata-rata populasi atau nilai variabel dependen berdasarkan nilai variabel independen yang diketahui.

\begin{tabular}{|c|c|c|c|c|c|c|}
\hline \\
\hline \multirow{2}{*}{\multicolumn{2}{|c|}{ Model }} & \multicolumn{2}{|c|}{$\begin{array}{l}\text { Unstandardized } \\
\text { Coefficients }\end{array}$} & \multirow{2}{*}{$\begin{array}{c}\text { Standardized } \\
\text { Coefficients } \\
\text { Beta } \\
\end{array}$} & \multirow[t]{2}{*}{$\mathrm{T}$} & \multirow[t]{2}{*}{ Sig. } \\
\hline & & B & Std. Error & & & \\
\hline \multirow{5}{*}{1} & (Constant) &,- 208 & ,226 & &,- 923 & ,362 \\
\hline & Leverage &,- 038 & ,018 &,- 316 & $-2,141$ & 038 \\
\hline & Ukuranperusahaan &, 006 & ,008 & ,116 &, 743 & ,462 \\
\hline & Kualitas audit & 031 & ,029 & 219 & 1,047 & ,302 \\
\hline & Independensi auditor & 051 & 027 &, 380 & 1,863 & 070 \\
\hline
\end{tabular}

Berdasarkan Tabel 4.2, diperoleh persamaan regresi linear berganda sebagai berikut :

$$
\mathrm{Y}=-0,208-0,038 \mathrm{X} 1+0,006 \mathrm{X} 2+0,031 \mathrm{X} 3+0,051 \mathrm{X} 4+\text { é }
$$

\subsection{Hasil Uji Hipotesis}

\subsubsection{Uji Signifikansi Simultan (Uji F)}

Uji simultan (Uji Statistik F) digunakan untuk menunjukkan apakah semua variabel bebas yang dimasukkan dalam model mempunyai pengaruh secara bersama-sama terhadap variabel terikat/dependen. Hasil pengujian uji simultan (Uji F) dalam penelitian ini ditunjukkan dalam tabel dibawah:

\begin{tabular}{|c|c|c|c|c|c|c|}
\hline \multicolumn{7}{|c|}{$\begin{array}{c}\text { Table 4.3.1 } \\
\text { Hasil Uji Simultan }(\text { Uji F }) \\
\text { ANOVA }^{\mathrm{a}}\end{array}$} \\
\hline Model & & Sum of Squares & df & Mean Square & $\mathrm{F}$ & Sig. \\
\hline \multirow{3}{*}{1} & Regression & ,033 & 4 & ,008 & 1,968 &, $118^{\mathrm{b}}$ \\
\hline & Residual & , 169 & 40 & ,004 & & \\
\hline & Total & ,202 & 44 & & & \\
\hline
\end{tabular}

Berdasarkan tabel 4.3 diketahui nilai $\mathrm{F}$ hitung adalah 1,968 dan sig 0,118. Karena nilai $\mathrm{F}$ hitung 1,968 < F tabel 2,60, Sig 0,118 > 0,05 maka dapat disimpulkan bahwa leverage, ukuran perusahaan, kualitas audit, dan indenpendensi auditor secara simultan tidak berpengaruh signifikan terhadap manajemen laba.

\subsubsection{Uji Parsial (Uji T)}

Uji statistik t pada dasarnya menunjukkan seberapa jauh pengaruh satu variabel penjelas/independen secara individual dalam menerangkan variasi variabel dependen.Kriteria yang digunakan dalam mengambil keputusan yaitu apabila $t$ hitung $>\mathrm{t}$ tabel pada $\mathrm{a}=5 \%$ dan nilai probabilitas <level of significant sebesar 0,05 maka variabel independen berpengaruh terhadap Vol : 7, no 2, 2019 Jurnal Akuntansi Keuangan dan Perpajakan Indonesia 
variabel dependen. Namun apabila $t$ hitung $<\mathrm{t}$ tabel pada $\mathrm{a}=5 \%$ dan nilai probabilitas $>$ level of significant sebesar 0,05 maka variabel independen tidak berpengaruh terhadap variabel dependen. Berikut hasil pengujian untuk uji parsial (Uji t).

Table4.3.2

Hasil Uji Parsial (Uji t)

Coefficients $^{\mathrm{a}}$

\begin{tabular}{|c|c|c|c|c|c|c|}
\hline \multirow{2}{*}{\multicolumn{2}{|c|}{ Model }} & \multicolumn{2}{|c|}{$\begin{array}{c}\text { Unstandardized } \\
\text { Coefficients }\end{array}$} & \multirow{2}{*}{$\begin{array}{c}\text { Standardized } \\
\text { Coefficients } \\
\text { Beta } \\
\end{array}$} & \multirow[t]{2}{*}{$\mathrm{T}$} & \multirow[t]{2}{*}{ Sig. } \\
\hline & & B & Std. Error & & & \\
\hline \multirow{5}{*}{1} & (Constant) &,- 208 &, 226 & &,- 923 & ,362 \\
\hline & Leverage &,- 038 & ,018 &,- 316 & $-2,141$ & ,038 \\
\hline & Ukuranperusahaan & ,006 & ,008 & ,116 & ,743 & , 462 \\
\hline & Kualitas audit & ,031 & ,029 & 219 & 1,047 & 302 \\
\hline & Independensi auditor &, 051 &, 027 & ,380 & 1,863 & 070 \\
\hline
\end{tabular}

\subsection{Pembahasan}

Hal ini dapat disimpulkan bahwa pengaruh yang diberikan oleh variabel leverage, ukuran perusahaan, kualitas audit dan independensi auditor terhadap manajemen laba hanya sebesar $16,4 \%$. Untuk sisanya sebesar $83,6 \%$, variabel manajemen laba dipengaruhi oleh variabel lain yang tidak diteliti dalam penelitian ini. Sementara itu, hasil penelitian yang diperoleh dari uji $\mathrm{F}$ menunjukkan bahwa nilai $F$ hitung sebesar 1,986 < F tabel 2,60 dengan signifikansi 0,118>0,05. Dapat disimpulkan bahwa leverage, ukuran perusahaan, kualitas audit dan independensi auditor secara simultan tidak berpengaruh signifikan terhadap manajemen laba.

\section{Kesimpulan, Implikasi dan Batasan}

\subsection{Kesimpulan}

Variabel leverage, ukuran perusahaan, kualitas audit, dan indenpendensi auditor tidak berpengaruh secara simultan terhadap manajemen laba pada perusahaan manufaktur yang terdaftar di BEI 2015-2017.

\subsection{Keterbatasan}

Variabel yang digunakan dalam penelitian ini tidak ada yang berpengaruh secara simultan terhadap manajemen laba pada perusahaan manufaktur.

\subsection{Saran}

Dengan memperhatikan keterbatasan yang ada, berikut ini beberapa saran yang diberikan.

1. Perlu adanya keselarasan fungsi dan tanggung jawab baik dari pihak pemilik (principal) maupun dari pihak pengelola/manajemen (agent) sehingga kemungkinan terjadinya praktik manajemen laba karena adanya motivasi yang berbeda atau kepentingan pribadi bisa diminimalisir dengan baik.

2. Pada peneliti selanjutnya dapat mengembangkan model penelitian yang digunakan dalam penelitian ini, baik dengan menambahkan variabel yang lain seperti Information Asymmetry, Firm Age, Growth dan faktor - faktor lainnya yang belum termasuk dalam penelitian ini dan dapat menggunakan referensi penelitian yang lebih terbaru baik referensi nasional maupun internasional.

\section{Reverensi}

Agoes, Sukrisno. 2017. “Auditing” Jakarta :SalembaEmpat 
Agustia, Y.P. and Suryani, Elly.(2018), PengaruhUkuran Perusahaan, Umur Perusahaan, Leverage danProfitabilitasterhadapManajemenLaba (StudipadaperusahaanPertambangan yang terdaftar di BEI periode 2014-2016).JurnalAset (AkuntansiRiset). 10 (1), 2018, 63-74.

Alijoyo, A \&Zaini, S. 2004. KomisarisIndependen :PenggerakPraktikGCG di Perusahaan.Jakarta : Gramedia.

Christiani, Ingrid danNugrahanti, Yeterina W. 2014."PengaruhKualitas Audit TerhadapManajemenLaba”.JurnalAkuntansidanKeuangan, Vol. 16.No. 1, ISSN. 1411-0288, 5256.

De Angelo, Linda Elizabeth. 1981. Auditor size and Audit Quality. Journal of Accounting and Economics 3 (1981) 183-199.

Dechow, P.M., R.G., Sloan, dan A.P Sweeney . 1995. Detecting Earnings Manajemen. Accounting and Business Research. Vol. 70 No. 2

Dj. Alfredo Mahendra.dkk. 2012. Pengaruhkinerjakeuanganterhadapnilaiperusahaanpadaperusahaamanufaktur di bursa efekIndonesia.juralmanajemen, strategibisnis, dankewirausahaan. Vol 6 no. 2 page : 130-138.

Fahmi, Irham.(2014). StudiKelayakanBisnis Dan KeputusanInvestasi, Jakarta, MitraWacana Media

Fuadillah, Dzulkifli. Pengaruh Leverage, Ukuran Perusahaan, Dan Kualitas Audit TerhadapManajemenLaba (StudiEmpirispada Perusahaan Manufaktur Yang Terdaftar Di BEI Periode 2008-2013). Skripsi.UniversitasNegeri Surabaya.

Gerayli, M., Ma'atofa, S., \&Yane Sari, A.M. (2011)."Impact of audit quality on Earnings Management: From Iran”. International ResearchJournal of Finance and Economics, Issue 66,pp. 77-84.

Ghozali, Imam. (2013), AplikasiAnalisis Multivariate dengan program IBM SPSS 25. Semarang: BadanPenerbitUniversitasDiponegoro.

Gul, Ferdinand A., Bikki L. Jaggi, and Gopal V. Krishnan. 2005. Auditor Independence: Evidence on the Joint Effect of Auditor Tenure and Nonaudit Fees. Auditing: A Journal of Practice and Theory, Vol. 26 No. 2, November, 2007, pp. 117-142.

Hamdani, Muliawan. 2009. "PentingnyaLaporanKinerjaKeuangan yang JujurdanPembenahan Internal.

Halim, J., Carmel Meiden, dan Rudolf L. Tobing. 2005. Pengaruh Manajemen Laba pada Tingkat Pengungkapan Laporan Keuangan pada Perusahaan Manufaktur yang Termasuk dalam Indeks LQ-45. Simposium Nasional Akuntansi VIII, Solo, 15-16 September, 2005.

Handayani, RR Sri danRachadi, AgustonoDwi. 2009. "PengaruhUkuran Perusahaan TerhadapManajemenLaba. “JurnalBisnisdanAkuntansi, Vol. 11, No. 1, 33-56.

Hardiyanti, Nia. 2012. Analisispengaruh Insider ownershi, leverage, profitability, firm size, dandeviden payout ratio terhadapnilaiperusahaan (studipadaperusahaanmanufaktur yang terdaftar di bei 2007-2010). Skripsi.UniversitasDiponegoro Semarang.

Isnanta, $\quad$ R. $2008 . \quad$ Skripsi.Pengaruh Corporate Governance danStrukturKepemilikanTerhadapManajemenLabadanKinerjaKeuangan.

JuniartidanCorolina.(2005), AnalisaFaktor-Faktor Yang BerpengaruhTerhadapPerataanLaba (Income Smoothing) Pada Perusahaan perusahaan Go Public.JurnalAkuntansidanKeuangan. ISSN: 1411-0288.

Kasmir.2008. Bank danLembagaKeuanganLainnya.EdesiRevisi 2008. Jakarta : PT. RAJAGRAFINDO PERSADA.

Klapper, L., Love. (2002). Corporate Governance, Investor Protection and Performance in Emerging Markets. Word Bank Working Paper, hal. 34-64 
Kusumawati.R danSudento, A. 2005.Analisispengaruhprofitabilitas (ROE), ukuranperusahaan (SIZE) dan Leverage keuangan (Solvabilitas) Terhadap underpricing padapenawaranperdana (Initial Public Offering / IPO) di Bursa Efek Indonesia.Utilitas. Vol. 13.No. 1.Page : 93-110.

Luhgiatno.(2010). “AnalisisPengaruhKualitasAuditTerhadapManajemenLaba (Studi Pada Perusahaan Yang Melakukan IPO diIndonesia)", Fokus $\quad$ Ekonomi, Vol. 5, No. 2.

Mayangsari, Sekar. 2004. AnalisisPengaruhIndependensi, Kualitas Audit, Serta Mekanis-me Corporate Governance TerhadapIntegritasLaporanKeuangan. Simposium Nasional Akuntansi VI, Surabaya, 16-17 Oktober, 2003, hal: 1255-1269.

Meutia, Inten.(2004), "PengaruhIndependensi Auditor TerhadapManajemenLabauntuk KAP Big-5 dan Non Big-5”.JurnalRisetAkuntansi Indonesia.7(3), 333-350.

Munawir. 2014. AnalisisLaporanKeuangan. Yogyakarta : liberty.

Nihlati, HaniatundanMeiranto, Wahyu. 2014. “AnalisisPengaruhKualitas Audit TerhadapEarnings Management”. Diponegoro Journal Of Accounting, Vol. 3, No. 3. Hal.1

Pratama, I.G. BagusAnggadanI.G.BagusWiksuana. 2016. Pengaruhukuranperusahaandan leverage terhadapnilaiperusahaandenganprofitabilitassebagaivariabelmediasi.JurnalManagemenUnud. Vol 5 No. 2.ISSN. 2302-8912.

Ratmono, Dwi (2010), "ManajemenLabaRiildanBerbasisAkrual: Dapatkah Auditor yangBerkualitasMendeteksinya?’.SimposiumNasionalAkuntansi 13. Purwokerto.

Rudangga, I GustiNgurahGededanSudiarta, GedeMerta. 2016. Pengaruhukuranperusahaan, leverage, danprofitabilitasterhadapnilaiperusahaan. E-jurnalmanajemenunud.Vol . 5 no. 7 Page : 43944422. ISSN. 2302-8912.

Rusmin (2010), “Auditor Quality and EarningsManagement: Singaporean Evidence”, Managerial Auditing Journal, 25(7), 618-638.

Santana, D.K.W. danWirakusuma, M.G. (2016), PengaruhPerencanaanPajak, KepemilikanManajerialdanUkuran Perusahaan terhadapPraktekManajemenLaba. E-JurnalAkuntansiUniversitasUdayana. ISSN: 2302-8559.

Sartono, Agus. 2001. ManajemenKeuangan“ TeoridanAplikasi”. EdisiEmpat. Yogyakarta: BPFE

Setiawati, L., \&Na'im, A. (May 2001), "Bank Health Evaluation by Bank Indonesia andEarnings Management in Banking Industry”, GadjahMadaＩnternational Journal of Business.3(2), 159-176

Sjahrial, Dermawan, (2009). ManajemenKeuangan. EdisiTiga. Jakarta: MitraWacana Media.

Siregar, S. V., dan S. Utama. 2006. PengaruhStrukturKepemilikan, ukuran Perusahaan, danPraktek Corporate Governance terhadapPengelolaanLaba (Earnings Manage-ment). JurnalRisetAkuntansi Indonesia, Vol. 9 No. 3, September, 2006, hal: 307-326.

Sulistyanto, H. Sri, danHaris Wibisono.2008. Good Corporate Governance: BerhasilkahDiterapkan di Indonesia.

Suwito, Edydan Arleen Herawaty.2005. AnalisisPengaruhKarakteristik Perusahaan TerhadapTindakanPerataanLaba yang Dilakukanoleh Perusahaan Yang Terdaftar Di Bursa Efek Jakarta.SimposiumNasional Akuntansi VIII. Solo. 15-16 September.

Tampubolon,R. 2005. Risk and System-Based Internasional Audit. Jakarta: Alex Media Komputolido

Utari, N.P.L.A. dan Sari, M.M.R. (2016), PengaruhAsimetriInformasi, Leverage, KepemilikanManajerial Dan KepemilikanInstitusionalPadaManajemenLaba. E-JurnalAkuntansiUniversitasUdayana. ISSN: 2302-8556, Vol.15.3. Juni (2016): 1886-1914. 
Wardani, Nuvika. 2018. Pengaruh struktur kepemilikan, ukuran perusahaan, dan kebijakan hutang terhadap nilai perusahaan pada perusahaan manufaktur yang terdaftar di Bursa Efek Indonesia Tahun 20131015. Skripsi. Universitas Muhammadiyah Ponorogo.

Watkins. Ann L, Hillison, William, Morecroft, Susan E. (2004), Audit Quality: A Synthesis Of Theory and Empirical Evidence. Journal Of Accounting Literature, Vol 23 pp.153-193.

Widyanigdah A.U. 2001. AnalisisFfaktor-Faktor yang BerpengaruhTerhadapEarning ManagementPada Perusahaan Go Publik di Indonesia.JurnalAkuntansi\&Keuangan, Vol. 3, No. 2, 89-101

Zhou, J., and Elder, R. (2001). "Audit Firm Size,Industry Specialization and Earnings Management by Initial Public Offering Firms"SUNY at Binghamton working paper 